\title{
O USO DE FERRAMENTA SÍNCRONA NA COLETA DE DADOS NA PESQUISA EM EDUCAÇÃO ONLINE
}

\author{
LA HERRAMIENTA SÍNCRONO PARA SU USO EN LA COLECCIÓN DE DATOS EN \\ LÍNEA DE BÚSQUEDA DE EDUCACIÓN
}

\author{
THE SYNCHRONOUS TOOL FOR USE IN DATA COLLECTION IN SEARCH ONLINE \\ EDUCATION
}

\author{
Ibsen Mateus BITTENCOURT ${ }^{1}$ \\ Eraldo Souza FERRAZ ${ }^{2}$ \\ Luís Paulo Leopoldo MERCADO ${ }^{3}$
}

RESUMO: O artigo descreve as características do MSN, apresenta o histórico de como foi desenvolvido e suas possibilidades de uso na educação online. Relata a experiência vivida através de uma entrevista realizada com uma professora pesquisadora em educação tecnológica fazendo uso do MSN. Apresenta as dificuldades nessa coleta. Traz considerações quanto à importância e limitações do MSN na coleta de dados da pesquisa online.

PALAVRAS-CHAVE: Pesquisa online. Coleta de dados online. Educação online.

RESUMEN: El artículo describe las características de MSN, muestra la historia de cómo se desarrolló y sus posibilidades de uso en la educación en línea. Informes de la experiencia vivida a través de una entrevista con un profesor investigador en la tecnología de fabricación de la educación el uso de MSN. Presenta dificultades en esta colección. Trae consideraciones con respecto a la importancia y las limitaciones de la recolección de datos de MSN de búsqueda en línea.

PALABRAS CLAVE: Investigación en línea. La recolección de datos en línea. La educación en línea.

\footnotetext{
1 Universidade Presbiteriana Mackenzie (UPM), São Paulo - SP - Brasil. Doutor em Administração de Empresas (Mackenzie-SP), Mestre Educação Brasileira na linha de Tecnologia da Informação e Comunicação (UFAL), MBA em Gestão de Turismo (UBM-RJ), Especialista em Matemática (UFPE), Bacharel em Administração de Empresas (UFAL) e Bacharel em Turismo (CESMAC). É Professor Adjunto II da Universidade Federal de Alagoas - UFAL. ORCID: 〈https://orcid.org/0000-0002-6543-143X>. E-mail: ibsen.ead@gmail.com

${ }^{2}$ Universidade Federal de Alagoas (UFA), Maceió - AL - Brasil. Pós-graduado em Educação através do Programa de Pós-Graduação do Centro de Educação. Graduado em Pedagogia foi obtida pela Universidade Federal de Pernambuco (1985) e a Especialização em Metodologia do Ensino Superior pela Universidade Católica de Pernambuco (1987). ORCID: <https://orcid.org/0000-0002-2311-601X>. E-mail: ferraz_pe@hotmail.com

${ }^{3}$ Universidade Federal de Alagoas (UFA), Maceió - AL - Brasil. Professor Titular com atuação na graduação em Educação Física e Pedagogia e na Pós-Graduação (Mestrado e Doutorado em Educação). Bolsista Produtividade em Pesquisa 2 do CNPq. Doutor em Educação (PUC/SP, 1998), Mestre em Educação (UFSM, 1993), Especialista em Formação de Professores em Mídias na Educação (UFAL, 2010), Licenciado em Ciências Biológicas Licenciatura Plena (UFSM, 1989). Bacharel em Direito (CESMAC, 2012). ORCID: <http://orcid.org/0000-0001-8491-6152>. E-mail: luispaulomercado@gmail.com
} 
ABSTRACT: The article describes the features of MSN, shows the history of how it was developed and its possibilities of use in online education. Reports the experience lived through an interview with a teacher researcher in technology education making use of MSN. It presents difficulties in this collection. Brings considerations regarding the importance and limitations of the MSN data collection of online search.

KEYWORDS: Online research. Online data collection. Online education.

\section{Introdução}

As tecnologias da comunicação e informação (TIC) têm proporcionando cada vez mais ao acesso à interação homem x máquina. Mais recentemente, o processo de comunicação tem sido viabilizado pelas ferramentas síncronas e assíncronas tais como: Messenger, blog, twitter, sala de bate-papo, e-mail, skype, dentre outras. Dentre estas, o Messenger e o e-mail são mais utilizadas com maior frequência pelos internautas. Estes, por sua vez, já as utilizam para uma simples conversa online, escrita ou oralmente, sem nenhum caráter científico.

Entretanto, existe àqueles que as utilizam para desenvolver estudos e pesquisas para o desenvolvimento de teses, fruto de uma atividade acadêmica, principalmente nos cursos de pós-graduação.

E com este intuito, tivemos a oportunidade de relatar nossa experiência, enquanto alunos na disciplina "Seminário de Pesquisa Online II, do Mestrado em Educação Brasileira da Universidade Federal de Alagoas, no $1^{\circ}$ semestre de 2009, quanto ao uso da ferramenta Messenger na coleta de dados. O grande objetivo dos professores responsáveis pela mencionada disciplina era o de fazer com que os alunos experimentassem as possibilidades de uso das ferramentas online existentes, para a coleta de dados buscando identificar as facilidades e dificuldades.

Ao grupo foi indicado um artigo que versava sobre "O Programa de Jovens Empreendedores" de autoria de uma pesquisadora do Mestrado em Educação da Universidade Federal de Alagoas (UFAL), fruto de sua dissertação de mestrado. Com base neste trabalho, deveríamos realizar uma entrevista online através do Messenger. Para tanto, foram elaboradas 17 questões e agendado o melhor dia para a concretização da atividade.

$\mathrm{O}$ artigo descreve as características do Messenger, apresenta o histórico de como foi desenvolvido e suas possibilidades de uso na educação online. Relata a experiência vivida através de uma entrevista realizada com uma professora pesquisadora em educação tecnológica fazendo uso do Messenger. Apresenta as dificuldades nessa coleta. Traz 
considerações quanto à importância e limitações do Messenger na coleta de dados da pesquisa online.

\section{Características da Ferramenta MSN e Possibilidades do uso}

O MSN foi desenvolvido pela Microsoft Corporation para ser um programa de mensagens instantâneas que permite ao usuário conectado à internet se relacionarem com outras pessoas de forma sincrônica em tempo real. Para isso, é necessário que ambos os participantes estejam conectados à Internet. Várias versões do programa foram desenvolvidas para deixar mais leve e de fácil acesso, como o Windows Messenger que originou o Windows Live Mensseger e o MSN Web Mensseger permitindo um acesso mais rápido e fácil do usuário aos recursos disponibilizados, usando um navegador Web de qualquer computador e qualquer lugar, sem a necessidade de instalar o software, pois nas primeiras versões era necessária a instalação do software para poder ser utilizado.

Os programas de envio de mensagens instantâneas revolucionaram o mundo das comunicações em 1996 quando um grupo de jovens israelenses criou e desenvolveu um dos primeiros programas de mensagens instantâneas da Internet, o ICQ trazendo uma nova forma de comunicação na Web. A sigla é um acrônimo, que significa em português eu procuro você. No início, foi uma febre na qual, muitos jovens se comunicavam, porém, existiam muitas limitações da ferramenta a qual era muito estática e não tinha muita interatividade. Mas, nos últimos anos, o MSN vem conseguindo um número maior de seguidores em muitos países e, no Brasil. O sucesso do MSN se dá por ter interface que possibilita a utilização dentro do ambiente Windows sendo um serviço integrado ao e-mail Hotmail e muito utilizado pelo público jovem para bate-papo na internet.

Para conseguir acessar o MSN é preciso ter um login que pode ser um dos e-mails conveniados para poder usufruir de todos os benefícios da interface. A tela inicial, conforme figura 1 mostra o local em que devemos colocar o endereço de e-mail e senha para poder acessá-lo com uma série de recursos. A interface é bastante interativa porque propicia uma logicidade e uma usabilidade muito boa. O usuário pode classificar seus contatos como: colegas, família, trabalho, pessoal, dentre outros. É possível editar o nome e o perfil do usuário, podendo ainda manter-se com status online ou off-line. Já é possível utilizar mensagens de texto, áudio e vídeo. Existem alguns recursos disponibilizados nas versões mais novas do MSN tais como: acesso remoto, áudio e videoconferência, que interligados com outros programas, tem-se a opção de gravar as conversas de áudio e vídeo. 

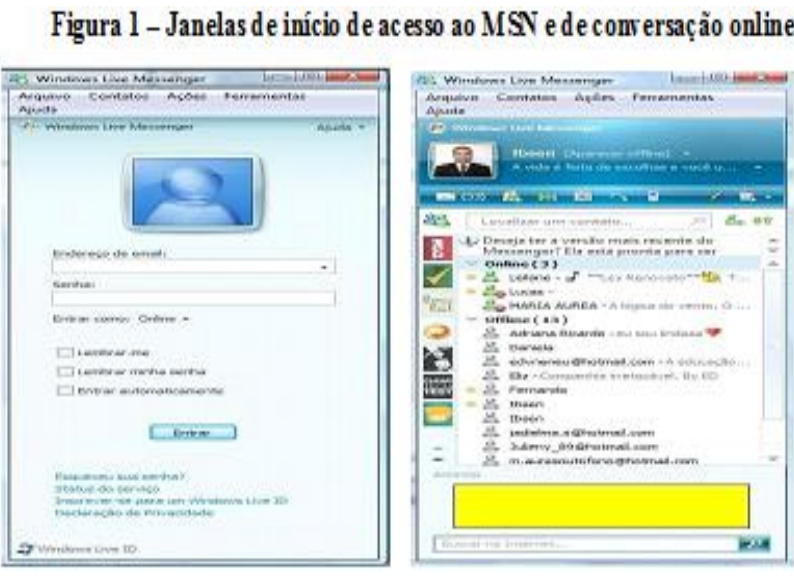

Figura 2 - Status de conversacão do MSN

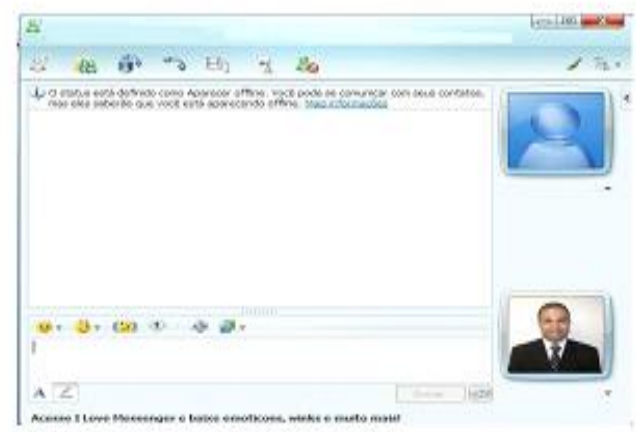

Fonte: http://download.live.com/messenger

Todas as ferramentas do MSN são acessadas a partir da caixa de mensagens que pode ser acessada ao clicar no nome de um dos contatos que pertence à lista do usuário. Na figura 2 verifica-se que existe uma caixa de texto na parte inferior, onde são digitadas as mensagens e na parte superior temos alguns ícones onde dar acesso para convidarmos uma pessoa ou um grupo de pessoas para participarem de um áudio e/ou videoconferência.

Segundo Leite e Migliora (2006), o MSN é visto pela maioria dos usuários como forma de lazer, ferramenta que envia e recebe mensagens instantâneas e que pessoas possam se conhecer e interagir. Autores como Prado (2001), Mercado (2005) e Cruz (2006) defendem o uso da ferramenta chat como possibilidade de estratégia de ensino para ajudar na aprendizagem do aluno.

\section{Possibilidades do uso do MSN na pesquisa em educação online}

O Chat possibilita a comunicação de pessoas que estão separadas em espaço e tempo de forma que as mesmas possam manter um diálogo de forma síncrona. A dinâmica da ferramenta envolve o envio e recebimento de mensagens de forma síncrona, na qual possa ser discutido, comentado ou ter conversas longas. Na educação podemos utilizar como parte do processo de ensino-aprendizagem, para captar conhecimentos e aprofundar conteúdos que tenham sido trabalhados em sala de aula.

O chat pode ser usado pelo professor para debater assuntos com os alunos, tirar dúvidas fora do horário das aulas; marcar horários para se encontrarem virtualmente, marcar encontros com especialistas ou análise de problemas de diferentes pontos de vistas, recurso para realização de atividades em aula ou fora da aula, como por exemplo, o professor pode solicitar aos alunos que assistam a um vídeo ou leiam um texto sobre determinado assunto e façam 
uma análise crítica sobre o tema proposto no chat e que troquem ideias e discutam suas opiniões e em seguida a turma faça uma síntese do tema (MERCADO, 2008, p. 3).

Para Cruz (2006), a aplicação do chat na educação, está na possibilidade de compartilhar informações em tempo real (ao mesmo tempo em lugares diferentes ou não) servindo de plataforma para debates, discussões, análise de alguns problemas, desde diferentes pontos de vista.

Para Prado (2001) o encontro online pode caracterizar-se como um momento criativo, construído coletivamente para gerar novas ideias e temas a serem estudados e aprofundados.

Didaticamente, o chat pode ser utilizado como uma ferramenta muito poderosa para que pessoas possam comunicar-se através de diálogos ou conversas em grupos entre os integrantes através da escrita e reescrita, fazendo comentários, respondendo a perguntas e fazendo questionamentos. A comunicação pode ser escrita ou não escrita, verbal ou não verbal, visual ou não visual, através de textos, áudio e/ou imagens. É muito importante saber conduzir um chat para que as pessoas envolvidas não fujam da temática estabelecida, por isso é importante a participação de um moderador, podendo ser um professor, tutor ou até mesmo um monitor ou aluno.

Em um chat é muito comum a utilização de nickname, ou seja, nome que os usuários colocam e querem ser associados a eles. Para Cruz (2006, p. 117), a utilização desses nicks é um dos grandes identitários da Internet; é uma das principais características que têm sido associadas às questões das identidades virtuais. As abreviações, acrônimos e emoticons também são muito utilizados em um chat, devido à rapidez com que os participantes respondem às perguntas e aos questionamentos.

Uso de "emoticons" - a escrita no chat desenvolveu uma própria simbologia, os conhecidos emoticons, pequenos conjuntos de caracteres que transmitem uma emoção ou estado de espírito durante um chat. Conhecidos comumente como carinhas, as quais enfatizam a parte expressiva da mensagem: ( , :-o, :D, :*), com a intenção de transmitir ao receptor uma reação que de outra maneira não seria possível. Assim temos as gargalhadas, as dúvidas, o choro, o abraço no ciberespaço (MERCADO, 2008, p.3).

No quadro 1 temos os exemplos de vários emoticons utilizados em salas de bate papo. 
Quadro 1 - Lista de Emoticons

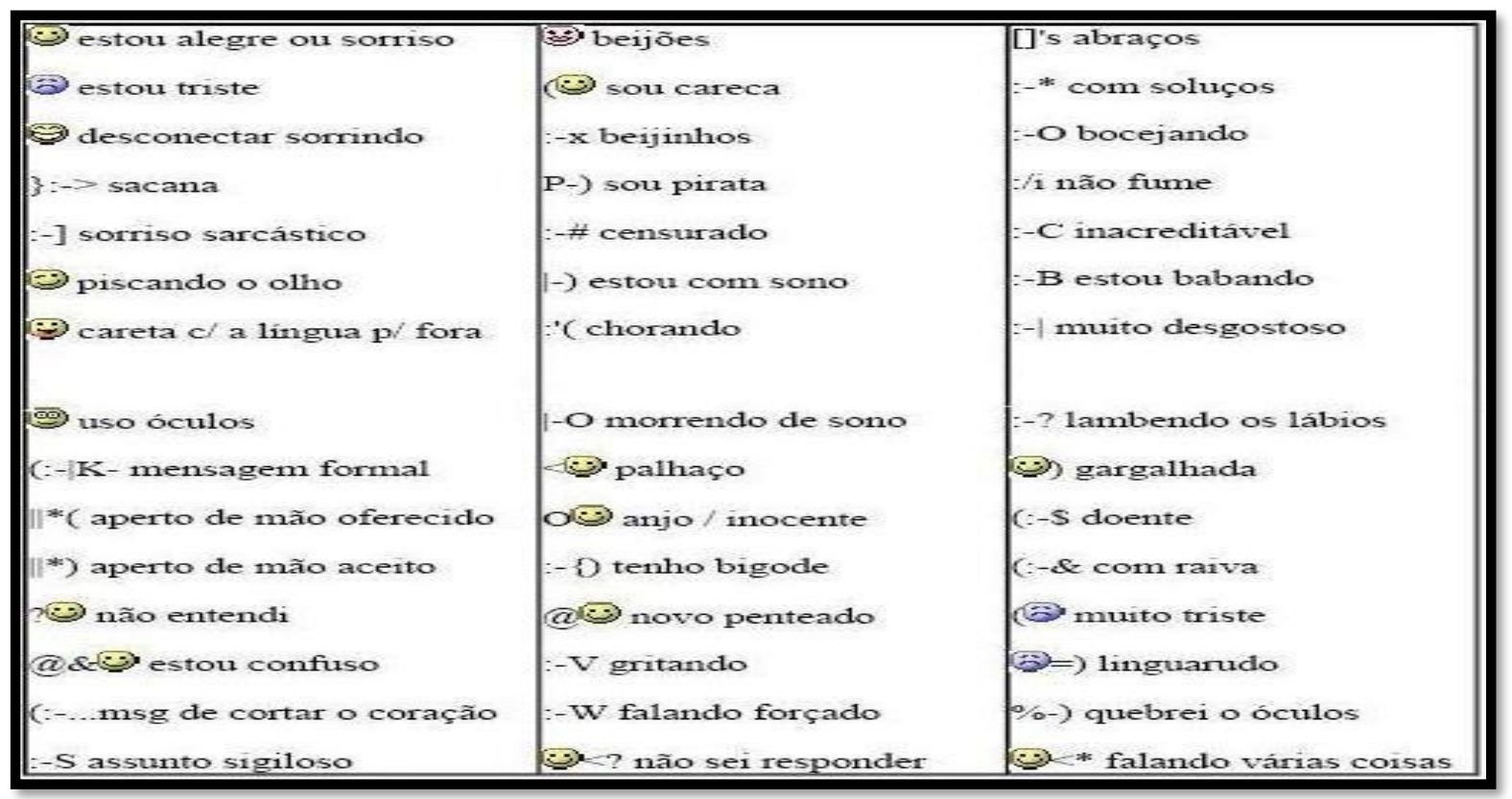

Fonte: http://saladeaulainterativa.pro.br/moodle/mod/book/print.php?id=2605

Os emoticons servem para representar algum tipo de gesto, emoção, afeto ou sentimento que não poderia ser escrita, servem para facilitar a comunicação e para minimizar o tempo de escrita, assim como os acrônimos que são comumente utilizados em chat, (EMHO para dizer 'em minha humilde opinião'). Os acrônimos são derivados do inglês e foram universalizados pela internet e utilizados em qualquer língua, muitos poucos são utilizados em português. $\mathrm{O}$ que se vê bastante são abreviações: como vc= você, tbm ou $\mathrm{Tb}=$ também, hj= hoje, $\mathrm{kd}=$ cadê, $\mathrm{pq}=$ porque, e etc.

Para Cruz (2006 p.11), Mercado (2005 p. 54) o tempo ideal para um chat é de 60 minutos, podendo ser estendido por até 90 minutos. Um chat muito longo tende aos participantes fugirem da temática proposta inicialmente. $\mathrm{O}$ ideal, enquanto estratégia didática, seria de grupos de alunos entre 4 a 6 participantes para que não fiquem tão dispersos.

O MSN, diferente de outros chats, foi um dos pioneiros em incorporar interfaces que possibilitam e permitem maior interação, entre os usuários. Na Tabela 1 temos vários exemplos de interfaces com suas vantagens e desvantagens: 
Tabela 1 - Vantagens e Desvantagens das Interfaces do MSN

\begin{tabular}{|c|c|c|}
\hline IN1 & VANT & $\mathbf{E N}$ \\
\hline $\begin{array}{l}\text { Compartilhamento de } \\
\text { Pastas }\end{array}$ & $\begin{array}{l}\text { Permiti compartilhar arquivo } \\
\text { de diferentes formatos. }\end{array}$ & $\begin{array}{l}\text { Não suporta arquivos } \\
\text { pesados, com extensões: } \\
\text { EXE, BAT, COM }\end{array}$ \\
\hline Áudio-conferência & $\begin{array}{l}\text { Possibilita interação com } \\
\text { áudio }\end{array}$ & Limite de usuários, ruídos. \\
\hline Vídeo-conferência & Interação de áudio e vídeo. & $\begin{array}{l}\text { Não permite mais que duas } \\
\text { pessoas. }\end{array}$ \\
\hline Celular & $\begin{array}{l}\text { Enviar e receber } \\
\text { no mensagens } \\
\text { desconectado. }\end{array}$ & $\begin{array}{l}\text { Pode ser cobrada uma taxa } \\
\text { pela operadora do celular. }\end{array}$ \\
\hline Ace & $\begin{array}{l}\text { Permite acesso remoto de um } \\
\text { computador para outro. }\end{array}$ & $\begin{array}{l}\text { em quanto } \\
\text { o. }\end{array}$ \\
\hline Jogo Online & $\begin{array}{l}\text { Permite que usuários joguem } \\
\text { em rede }\end{array}$ & $\begin{array}{l}\text { Limite de usuários } \text { e } \\
\text { poucos jogos } \\
\text { disponibilizados. }\end{array}$ \\
\hline le Mú & $\begin{array}{l}\text { rmite receber musica entre } \\
\text { uários. }\end{array}$ & $\begin{array}{l}\text { Download pode demorar e } \\
\text { vulnerabilidade a Trojan } \\
\text { (vírus). }\end{array}$ \\
\hline Envi & ceber vídeos entre & $\begin{array}{l}\text { Download pode demorar e } \\
\text { vulnerabilidade a Trojan. }\end{array}$ \\
\hline Mensagens Off-line & $\begin{array}{l}\text { Permite mesmo desconectado } \\
\text { que outros usuários enviem } \\
\text { mensagens. }\end{array}$ & $\begin{array}{l}\text { É assíncrono. (mais pode } \\
\text { ativar a interface para } \\
\text { receber no celular). }\end{array}$ \\
\hline Ligações Telefônicas & $\begin{array}{l}\text { Permite a partir dos contatos } \\
\text { fazer ligações. }\end{array}$ & $\begin{array}{l}\text { Pode ser cobr } \\
\text { pela operadora }\end{array}$ \\
\hline E-mail & Envio direto de e-mail. & Não tem. \\
\hline $\begin{array}{l}\text { Envio de wink } \\
\text { emoticons }\end{array}$ & $\begin{array}{l}\text { Expressa emoções } \\
\text { sentimentos. }\end{array}$ & $\begin{array}{l}\text { Muitos não entendem os } \\
\text { emoticons. }\end{array}$ \\
\hline Blog & Permite utilizar um blog & Não tem \\
\hline
\end{tabular}

Fonte: Os autores

A interação no MSN pode ser entre dois usuários ou mais, dependendo do tipo de interface que está sendo utilizada, mas isso só é possível se ambos os usuários tiverem versões compatíveis, caso contrário poderá ter problema de acessibilidade de alguma interface.

\section{Relato de experiência de coleta de dados usando MSN}

Numa das atividades previstas na disciplina "Seminário de Pesquisa Online" ofertada no $1^{\circ}$. Semestre de 2009, no Mestrado em Educação Brasileira da Universidade Federal de Alagoas, os professores planejaram a realização de uma entrevista online fazendo uso das possibilidades oferecidas pelas TIC tais como: MSN, blogs, chat, twitter, skype, dente outros. 
O grande objetivo dos professores era fazer com que seus alunos experimentassem a entrevista usando a ferramenta MSN na coleta de dados na tentativa de identificarem os aspectos facilitadores, bem como, as dificuldades.

Ao grupo foi indicada a utilização do MSN que envolveu ama professora-pesquisadora do Mestrado em Educação na linha das TIC por ter publicado um artigo tratando do "Programa Jovem empreendedor em Alagoas (JEP), e dois alunos do referido Curso de Mestrado. O trabalho da entrevistada descrevia a experiência do programa JEP, que utiliza a EAD com alunos do Ensino Médio nas escolas públicas. O objetivo era analisar as contribuições do programa, através da EAD, para a qualificação e inserção dos alunos concluintes do Ensino Médio no mercado de trabalho e investigar as potencialidades da EAD no ensino médio e as possibilidades fornecidas pelo JEP para a diminuição da exclusão digital. A pesquisa envolveu duas escolas localizadas na cidade de Maceió, tendo como universo da pesquisa 76 alunos e 2 instrutores.

Para a realização de nosso trabalho, como procedimento inicial, enviamos um roteiro com 17 questões para que a entrevistada tomasse conhecimento dos itens que comporiam a entrevista, dentre elas podemos citar: as dificuldades e vantagens para realização da pesquisa, como administrou as dificuldades, se a aplicação dos questionários ocorreu em tempo hábil, se todos os alunos da amostra responderam ao questionário, se os resultados da pesquisa comprovaram as hipóteses, como foi a coleta, tabulação e análise dos dados na pesquisa realizada por ela. Em seguida, foi escolhida a melhor data e hora para concretização da atividade.

A entrevista no MSN aconteceu no final de semana, com início às 16h30min e término às $17 \mathrm{~h} 25 \mathrm{~min}$, totalizando 55 minutos; tempo ideal para um bate-papo dessa natureza.

No quadro 2 apresentamos parte da entrevista que versava sobre as dificuldades, aplicação dos questionários e a participação dos respondentes.

Quadro 2 - Status da entrevista realizada pelo MSN

\begin{tabular}{|ll}
\hline Pesquisada diz: & 1. Quais as dificuldades para a realização da pesquisa? Como administrou essas dificuldades? \\
Pesquisada diz: & $\begin{array}{l}\text { Para a realização da pesquisa tive poucas dificuldades. O que me ajudou bastante foi ter uma aproximação } \\
\text { com o programa JEP e o universo da pesquisa. Eu estava inserida, uma vez que era instrutora do programa. A } \\
\text { maior dificuldade foi na realização das entrevistas, para conciliar horários. }\end{array}$ \\
Pesquisada diz: & lógico que sempre há um ou outro probleminha. \\
Pesquisadores diz: & Como administrou essas dificuldades? \\
Pesquisada diz: & os meus foram mais pessoais do que referentes a pesquisa \\
Pesquisadores diz: & 2. A aplicação dos questionários ocorreu em tempo hábil? Quais foram os entraves? \\
Pesquisada diz: & $\begin{array}{l}\text { Sim, mas ocorreu um atraso em função de problemas que tive de saúde. Um entrave foi para aplicá-los } \\
\text { pessoalmente e presencialmente. Mas já tinha ima boa base de depoimentos por e-mail. }\end{array}$ \\
Pesquisadores diz: & 3.Todos os alunos responderam os questionários? O que dificultou? \\
Pesquisada diz: & $\begin{array}{l}\text { Nenhum, dos que foram solicitados, se negou a responder. Ser instrutora do programa e conhecer os demais } \\
\text { instrutores facilitou tudo. }\end{array}$
\end{tabular}

Fonte: Os autores 
No quadro anterior, identificamos como facilitador da realização da atividade o fato da pesquisadora ter uma aproximação com o programa em estudo e estar inserida enquanto instrutora, mas que a conciliação dos horários foi colocada como a maior dificuldade. Salientamos que não é condição para a realização da entrevista o fato de ter amizade ou não, com o público-alvo da pesquisa, mas é sim, um dos elementos facilitadores. Foi perguntado se houve mais de um tipo de questionário aplicado, a entrevistada afirmou que fez uso sim, e que realizou observação participante. No quadro 3 consta trecho desse bate-papo.

\section{Quadro 3 - Status da entrevista online realizada pelo MSN}

\begin{tabular}{|c|c|}
\hline Pesquisada diz: & $\begin{array}{l}\text { 4.Houve mais de um tipo de questionário? Um fechado e um aberto? } \\
\text { Houve. Preferi trabalhar com questionário fechado e aberto. Para verificar se os dados que eu já dispunha com } \\
\text { a observação eram realmente fidedignos, aumentando sua validade. Também para responder, de modo } \\
\text { satisfatório e plausivel, a algumas questões que me foram surgindo. }\end{array}$ \\
\hline Pesquisada diz: & Também usei entrevistas \\
\hline Pesquisadores diz: & 5.Os resultados comprovaram suas hipóteses? \\
\hline Pesquisada diz: & $\begin{array}{l}\text { Na verdade foi aplicado um modelo de questionário com perguntas abertas e fechadas. Quanto a hipótese, } \\
\text { sim, ela foi confirmada. Além de ter a hipótese confirmada ficou claro que programas como o JEP podem } \\
\text { contribuir para a melhoria da educação básica, utilizando a ead e adotando o ensino do empreendedorismo, } \\
\text { proporcionando o acesso a diversas áreas do conhecimento. }\end{array}$ \\
\hline Pesquisadores diz: & 6. Com a aplicação dos questionários houve a possibilidade de entender a realidade? \\
\hline Pesquisada diz: & $\begin{array}{l}\text { Os questionários foram apenas um dos instrumentos utilizados. O que me possibilitou entender a realidade, de } \\
\text { fato, foi trabalhar com a observação participante e com entrevistas, estando inserida no trabalho como } \\
\text { instrutora (vivenciando cada dificuldade e cada conquista). }\end{array}$ \\
\hline
\end{tabular}

Fonte: Os autores

Nos dados do quadro 4, segue ainda as respostas obtidas quando foi perguntado sobre os procedimentos metodológicos utilizados pela entrevistada com relação à tabulação e à triangulação dos dados que, segundo Minayo (2005), confirma a hipótese investigada ou gera outras.

\section{Quadro 4 - Status da entrevista online realizada pelo MSN}

\begin{tabular}{|c|c|}
\hline Pesquisada diz: & $\begin{array}{l}\text { 4.Houve mais de um tipo de questionário? Um fechado e um aberto? } \\
\text { Houve. Preferi trabalhar com questionário fechado e aberto. Para verificar se os dados que eu já dispunha com } \\
\text { a observação eram realmente fidedignos, aumentando sua validade. Também para responder, de modo } \\
\text { satisfatório e plausível, a algumas questões que me foram surgindo. }\end{array}$ \\
\hline Pesquisada diz: & Também usei entrevistas \\
\hline Pesquisadores diz: & 5.Os resultados comprovaram suas hipóteses? \\
\hline Pesquisada diz: & $\begin{array}{l}\text { Na verdade foi aplicado um modelo de questionário com perguntas abertas e fechadas. Quanto a hipótese, } \\
\text { sim, ela foi confirmada. Além de ter a hipótese confirmada ficou claro que programas como o JEP podem } \\
\text { contribuir para a melhoria da educação básica, utilizando a ead| e adotando o ensino do empreendedorismo, } \\
\text { proporcionando o acesso a diversas áreas do conhecimento. }\end{array}$ \\
\hline Pesquisadores diz: & 6. Com a aplicação dos questionários houve a possibilidade de entender a realidade? \\
\hline Pesquisada diz: & $\begin{array}{l}\text { Os questionários foram apenas um dos instrumentos utilizados. O que me possibilitou entender a realidade, de } \\
\text { fato, foi trabalhar com a observação participante e com entrevistas, estando inserida no trabalho como } \\
\text { instrutora (vivenciando cada dificuldade e cada conquista). }\end{array}$ \\
\hline
\end{tabular}

Fonte: Os autores 
Foi perguntado à entrevistada como foi feita a tabulação dos dados coletados. Os questionários, bem como os dados foram separados manualmente e, a entrevistada, levou aproximadamente cinco meses para fazer esse trabalho. Além de ter sido feito tudo manualmente a entrevistadora ainda teve problemas pessoais que dificultaram, ainda mais, a finalização de sua pesquisa.

Ao final das perguntas que havíamos elaborado, indagamos sobre a percepção dela na experiência de participar de uma entrevista online. A entrevistada mesma afirmou "achei interessante e que não estava acostumada em usar o MSN e sim o e-mail. Perguntamos se a mesma recomendaria a outros pesquisadores a entrevista através do MSN e obtivemos como resposta: "recomendaria, pois é prático, porque facilita o acesso ao entrevistado, mesmo em espaços diferentes".

Cruz (2006) corrobora com a pesquisadora afirmando que a entrevista online pode ser bem útil quando se tem dificuldades de acesso à determinado grupo de pessoas, reduzindo assim gastos e tempo.

\section{Vantagens na coleta de dados online utilizando o MSN}

Uma das dificuldades que possam advir da utilização da ferramenta MSN na coleta de dados é o fato de o pesquisador não saber usá-la; mas isto não pode ser verdadeiro porque ao escolher essa ferramenta o indivíduo deverá demonstrar que tem o domínio e, se não o tem, primeiramente buscará a aprender os mecanismos de usabilidade.

Cruz (2006) apresenta como problemas no uso do chat:

1) Uso do teclado para comunicar-se pode converter-se em um elemento pesado;

2) Pessoas que têm dificuldade de redação sentem-se inibidas;

3) Pela velocidade da discussão, a participação pode não ser produtiva;

4) As vezes causa confusão pela falta de clareza das instruções que guiam a conversa.

Nessa experiência não identificamos dificuldades, mas, segundo Cruz (2006), isso se dá pela especificidade da utilização do MSN como possibilidade na coleta de dados na pesquisa online, ou seja, na entrevista não temos tanto ruído de informações que prejudiquem a digitação e a atenção dos participantes, entrevistado e entrevistando. 


\section{Considerações finais}

Nas pesquisas realizadas nas Ciências Humanas e, principalmente, na área da educação, o método de investigação deve ser realizado em todas as áreas com muito cuidado e seriedade, principalmente quando utilizamos as entrevistas online. Precisamos obter respostas fidedignas e ter garantias de que o entrevistado é, realmente, o sujeito da pesquisa; caso contrário, comprometeremos os resultados.

As TIC têm oportunizado, aos pesquisadores, várias possibilidades de coleta de dados. Esta é uma realidade que não podemos deixar de lado principalmente quem desenvolve pesquisa na área de educação online.

A grande maioria dos pesquisadores aponta como fator de dificuldades da entrevista a disponibilidade de tempo para deslocar-se até o entrevistando e realizar a atividade. Mas, o uso das ferramentas síncronas e assíncronas tem ajudado a diminuir essa dificuldade e porque não dizer, acabar.

Ao realizamos nossa pesquisa utilizando o MSN constatamos muito mais pontos facilitadores do que problemas. Isto pode ser justificado porque em tempo real, foi possível a obtenção das respostas elaboradas a partir de um planejamento prévio do que seria feito. A própria disponibilidade da entrevistada foi crucial para realização do nosso trabalho.

Finalizando, o artigo em questão aponta para um aprofundamento de outros fatores que poderão advir com o uso excessivo pelos pesquisadores que usarem o MSN com o objetivo de coleta de dados gerando dúvidas, aos leitores e instituições acadêmicas, quanto à confiabilidade e à veracidade de quem esteja fornecendo os dados coletados e, ainda, levantando as possibilidades de novos estudos quanto ao uso do MSN como ferramenta pedagógica na sala de aula em cursos a distância.

\section{REFERÊNCIAS}

CRUZ, W. B. Experiências utilizando ferramentas síncrona na educação. In: MERCADO, L. P. L. (Org.). Experiências com tecnologias da informação e comunicação na educação. Maceió: Edufal, 2006.

LEITE, C.; MIGLIORA, R. A troca sincrônica de mensagens (msn) nasocialização de crianças e adolescentes. 2006. Disponível em:

http://www.bemtv.org.br/portal/materiais/A_troca_sincronica_de_mensagens.pdf Acesso em 10 jan. 2010.

MERCADO, L. P. (Org.). Vivências com aprendizagem na internet. Maceió: Edufal, 2005. 
MINAYO, M. C. S. Introdução: conceito de avaliação por triangulação de métodos. In: MYNAYO, Maria Cecília S.; ASSIS, Simone Gonçalves; SOUZA, Edinilsa Ramos. (Org.). Avaliação por triangulação de método: abordagem de programas sociais. Rio de Janeiro: Fiocruz, v. 1, p. 19-52, 2005.

MINAYO, M. C. S. Interfaces de pesquisa, comunicação e socialização. Disponível em: http://saladeaulainterativa.pro.br/moodle/mod/book/print.php?id=2605. Acesso em: 10 jun. 2009.

PRADO, M. E. Educação a distância: os ambientes virtuais e algumas possibilidades pedagógicas. Salto para futuro/SEED/MEC. Brasília, MEC/SEED, 2001.

\section{Como citar este artigo:}

BITTENCOURT, Ibsen Mateus; FERRAZ, Eraldo de Souza; MERCADO, Luís Paulo Leopoldo. $O$ uso de ferramenta síncrona na coleta de dados na pesquisa em educação online. Revista Ibero-Americana de Estudos em Educação, Araraquara, v. 14, n. 3, p. 1217-1228, jul./set., 2019. e-ISSN: 1982-5587. DOI: 10.21723/riaee.v14i3.9053

Data de Submissão: 05/11/2016

Revisões requeridas: 10/04/2017

Aceite em: 10/08/2018

Publicado em: 11/05/2019 